\title{
Technology, Preference for Quality, and Vertical Intra-Industry Trade
}

\author{
Le Duc Niem, Taegi Kim \\ Department of Economics, Tay Nguyen University, Vietnam \\ Department of Economics, Chonnam National University, Gwangju, Korea \\ E-mail: leniem@gmail.com,tgkim@chonnam.ac.kr \\ Received July 26, 2010; revised August 31, 2010; accepted September 5, 2010
}

\begin{abstract}
This paper provides a simple theoretical model to investigate determinants of the vertical IIT based on Bertrand price competition. We find that the volume of trade is higher among countries where R\&D investments are larger. In addition, the vertical IIT share increases with the similarity between two countries in terms of technology and per-capita income. Our theoretical findings are consistent with recent empirical findings.
\end{abstract}

Keywords: Technology, Preference for Quality, Volume of Trade, Vertical Intra-Industry Trade

\section{Introduction}

Traditionally, trade is seen as being concentrated among industrialized countries, and consists principally of vertical intra-industry trade (IIT). For example, reference [1] found that trade within the countries of the Organisation for Economic Co-operation and Development (OECD) has increased at a much more rapid rate than has trade between OECD countries and the rest of the world. Additionally, reference [2] determined that more than 50\% of trade among EU countries was IIT, and that the intra-industry trade among EU countries was composed, in large part, of vertical IIT.

In explaining these characteristics of trade, most studies have emphasized economies of scale, product differentiation, and imperfect competition as the determinants of intra-industry trade. For example, seminal papers by $[3,4]$ developed this theoretical framework. However, these models pertain to horizontal product differentiation, assuming these products are identical in quality. Reference [5] considered a model where the North exports high quality products and the South exports low quality products, and evaluated the effects on trade of factors such as technical progress, income distribution, and population growth.

Reference [6] showed that aggregation across sectors induced a systematic bias against finding support for Reference [7] hypothesis, and argued that the Linder hypothesis should be formulated at the sector level, where intersectoral determinants of trade can be con- trolled for. As in part III of [6], our model focuses on trade of goods in a sector level. This paper is similar to [8] which explained the impact of preference diversity and relative country size on intra-industry trade in an industry with a vertically differentiated product. However, contrary to [8], which focuses on the effects of demand side on trade, this paper focuses on the effects of technology change on trade.

We consider two countries whose technologies differ from each other, and assume that consumers have different preferences for product quality resulting from differences in personal income. We determine that the vertical IIT share increases as the two countries become more similar in terms of technology as well as similar in per capita income. In addition, we find that volume of trade is higher among countries where R\&D investments are larger. For these reasons, we conclude that trade volume and vertical ITT will tend to concentrate in developed countries.

In Section 2 we give our basic model, and in Section 3 we derive the determinants of vertical IIT. Section 4 presents our conclusions.

\section{The Model}

\subsection{Consumers}

We consider an industry with a vertically differentiated product. There are two firms that produce functionally identical products, but of different quality. The products are sold to a population of consumers with different 
quality preferences. Each consumer may purchase a good from one of the firms, or none at all.

The consumer's utility when he consumes a good with $q$ units of quality and price $p$ is described as follows:

$$
U\left(J_{i}\right)=J_{i} q-p
$$

This function is an indirect utility function of consumer $i$, identified by the parameter $J_{i}$. The population of consumers is described by the parameter $J_{i}$, and is distributed uniformly between 0 and $b$. The parameter $b$ measures the heterogeneity in consumer preference for quality. Consumers will decide to purchase the good that gives a higher and non-negative utility.

Subscripts $H$ and $L$ denote high and low quality products, respectively, and give the corresponding quality level and price as $q_{H}, q_{L}$ and $p_{H}, p_{L}$. We denote $J_{L H}$ to be the marginal consumer who is indifferent with regard to consuming either of the two products. That is, the consumer, $J_{L H}$, satisfies

$U\left(q_{H}, p_{H}\right)=U\left(q_{L}, p_{L}\right)$. By Equation (1), the marginal consumer $J_{L H}$ is defined as:

$$
J_{L H}=\frac{\left(p_{H}-p_{L}\right)}{\left(q_{H}-q_{L}\right)}
$$

Some consumers do not wish to buy any goods at prevailing prices. We denote $J_{L}$ to be the consumer who is indifferent in terms of purchasing a low quality product and refraining from purchase. By Equation (1), this type of marginal consumer is defined as:

$$
J_{L}=\frac{p_{L}}{q_{L}}
$$

All consumers having $J_{i}>J_{L H}$ will buy high quality goods. All consumers having $J_{L H}>J_{i}>J_{L}$ will buy low-quality goods, and all consumers having $J_{i}<J_{L}$ will not buy any goods ${ }^{1}$.

\subsection{A Two-Country World}

For the sake of simplicity, we assume a world of only two countries: Home and Foreign. We assume that the technology level of Foreign is higher than that of Home. The quality level of the product will be determined by the technology level. Therefore, the higher technology of Foreign enables a firm to produce high quality products, and the lower technology of Home enables a firm to produce low quality products ${ }^{2}$. We assume that the quality of each product is a consequence of R\&D investment, but this quality cost has been sunk prior to price compe-

\footnotetext{
${ }^{1}$ See $[10,11]$.

${ }^{2}$ This assumption is the same as [5], which assumes that the level of product quality is determined by the level of technology.
}

tition stage. In addition, production costs of these goods are so small as to be negligible.

We let $q_{H}=Q$ and $q_{L}=k Q$, where $Q$ represents the highest technology available in our world, and parameter $\mathrm{k}$ measures the technology similarity between the two countries. Then $\mathrm{k}$ approaches 1 , the two countries become more and more similar in terms of technology. It is worthy noting that an increase in $Q$ implies that technology levels in both countries increase. Thus, $\mathrm{Q}$ can be used as a proxy for our world technology level (or regional technology level when we view the two countries as a region).

The populations of consumers in Home and Foreign are the same, and are normalized to 1 . However, consumers in each country differ in regard to their taste for quality. Home consumers are distributed uniformly in the interval of $(0, b)$, and foreign consumers are distributed uniformly in the interval of $\left(0, b^{*}\right)$. We assume that $b^{*} \geq b$, which means that the range of preference for quality is greater in Foreign than in Home. As conceptualized by [9], a preference for quality is dependent on consumers' income; the more income a consumer has, the more that consumer is willing to pay for any quality level. For this reason, income level of Home (or Foreign) can be considered a proxy for the $b$ (or $b^{*}$ ) variable. ${ }^{3}$ As preference diversity for quality is associated with income, an assumption of $b^{*} \geq b$ implies that the income level of Foreign is higher than that of Home. Thus, we call $h=b / b^{*}$ the relative income level of the two countries. It is noteworthy that $0<h \leq 1$ and $h$ approaching 1 means the two countries become similar in terms of income.

Each country exchanges its products with the other country. ${ }^{4}$ Home buys high quality products from Foreign, and Foreign buys low quality products from Home. Trade between the two countries can be illustrated as in Figure 1.

\subsection{Price Competition}

Imagine a game as follows. There are no trade barriers between Home and Foreign, and the two firms compete simultaneously in price. We assume that no price discrimination is possible because the goods can move freely without any transportation costs between the two countries.

\footnotetext{
${ }^{3}$ Consumer's preference diversity is caused by differences in income. Additionally, we assume that consumers in Home are uniformly distributed in [0,b] with regard to their preference. Thus, Home's per capita income is the average income of all of its consumers, which is directly proportional to the average of consumer's preference $b / 2$ or just $b$.

${ }^{4}$ We consider an integrated economy as in [12] for our two country world.
} 


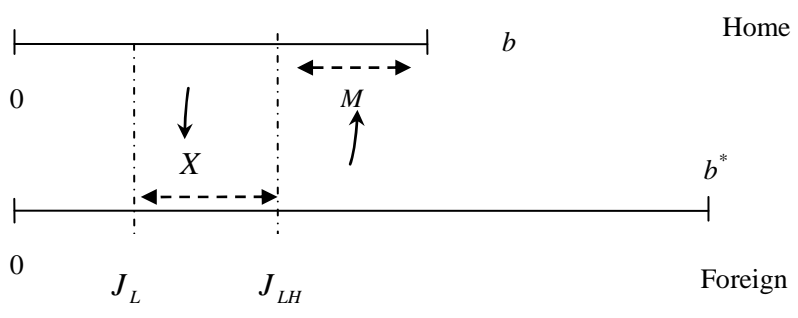

Figure 1. Trade between two countries.

Each consumer buys only one unit of goods, and thus the total demand for a good is determined by the number of consumers buying the goods. Based on Figure 1, the firms' demand functions are as follows:

$$
\begin{gathered}
D_{L}\left(p_{L}, p_{H}\right)=\left(\frac{1}{b}+\frac{1}{b^{*}}\right)\left[\frac{p_{H}-p_{L}}{q_{H}-q_{L}}-\frac{p_{L}}{q_{L}}\right] \\
D_{H}\left(p_{L}, p_{H}\right)=\left(\frac{1}{b}+\frac{1}{b^{*}}\right)\left[b-\frac{p_{H}-p_{L}}{q_{H}-q_{L}}\right]+\left(\frac{1}{b^{*}}\right)\left(b^{*}-b\right)
\end{gathered}
$$

The corresponding profit functions are as follows ${ }^{5}$ :

$$
\begin{aligned}
\prod_{L}\left(p_{L}, p_{H}\right) & =\left(\frac{1}{b}+\frac{1}{b^{*}}\right)\left[\frac{p_{H}-p_{L}}{q_{H}-q_{L}}-\frac{p_{L}}{q_{L}}\right] p_{L} \\
\prod_{H}\left(p_{L}, p_{H}\right) & =\left(\frac{1}{b}+\frac{1}{b^{*}}\right)\left[b-\frac{p_{H}-p_{L}}{q_{H}-q_{L}}\right] p_{H} \\
& +\left(\frac{1}{b^{*}}\right)\left(b^{*}-b\right) p_{H}
\end{aligned}
$$

The best response of the low quality firm $p_{L}^{*}$ is derived from the first order condition $\left(\partial \prod_{L} / \partial p_{L}=0\right)$, which is

$$
q_{L} p_{H}-2 q_{H} p_{L}^{*}=0
$$

Similarly, the best response of the high quality firm $p_{H}^{*}$ is derived from the first order condition $\left(\partial \prod_{H} / \partial p_{H}=0\right)$, which is

$$
\left(\frac{1}{b}+\frac{1}{b^{*}}\right)\left[\frac{b\left(q_{H}-q_{L}\right)-2 p_{H}^{*}+p_{L}}{q_{H}-q_{L}}\right]+\frac{1}{b^{*}}\left(b^{*}-b\right)=0
$$

The Nash Equilibrium is derived by solving (8) and (9) with $p_{L}=p_{L}^{*}$ and $p_{H}=p_{H}^{*}$. We have the optimal prices as follows:

$$
p_{L}^{*}=\frac{\tilde{b} q_{L}\left(q_{H}-q_{L}\right)}{4 q_{H}-q_{L}}
$$

${ }^{5}$ Note that quality costs do not affect the optimal responses of both firms in this stage.

$$
p_{H}^{*}=\frac{2 \tilde{b} q_{H}\left(q_{H}-q_{L}\right)}{4 q_{H}-q_{L}}
$$

Where $\tilde{b}=\frac{2}{(1 / b)+\left(1 / b^{*}\right)}$, which is the harmonic mean of $b$ and $b^{*}$.

\section{Determinants of Intra-Industry Trade}

Now we consider the trade flows between two countries. Recall from Figure 1 that Foreign exports high quality products to Home, and Home exports low-quality products to Foreign. The export value of Home, X, denotes the consumption of low quality products by Foreign. Similarly, the import value of Home, $\mathrm{M}$, is the consumption of high quality products manufactured in Foreign. Thus, we can write the exports and imports as follows:

$$
X=\frac{1}{b^{*}}\left[\frac{p_{H}-p_{L}}{q_{H}-q_{L}}-\frac{p_{L}}{q_{L}}\right] p_{L}
$$

and

$$
M=\frac{1}{b}\left[b-\frac{p_{H}-p_{L}}{q_{H}-q_{L}}\right] p_{H}
$$

Substituting (10) and (11) into (12) with $q_{H}=Q$ and $q_{L}=k Q$, we arrive at

$$
\begin{gathered}
X=\frac{\tilde{b}^{2}(1-k) k}{b^{*}(4-k)^{2}} Q \\
\text { and } \\
M=\frac{2 \tilde{b}^{2}(1-k)}{b(4-k)^{2}}\left[\frac{b(4-k)}{\tilde{b}}-(2-k)\right] Q
\end{gathered}
$$

The result in (13) implies that an increase in Q will increase both exports and imports. In other words, export and import values are higher when both goods are produced with higher quality (such that relative quality is kept unchanged). Furthermore, we note that $\mathrm{Q}$ can be viewed as a proxy for the technology level found in the two-country world. This is because as Q is higher, the technology levels in Home and Foreign are both higher. Since this technology level is a consequence of the past $\mathrm{R} \& \mathrm{D}$ effort, we arrive at the following proposition.

Proposition 1: Both exports and imports increase in $R \& D$ investment for quality innovation.

More than $80 \%$ of the world R\&D investments are conducted in high income OECD countries. ${ }^{6}$ Proposition 1 explains why higher trade volumes were observed between high income countries.

Now we consider the share of IIT. We use the follow-

${ }^{6}$ http://www.nsf.gov/statistics/seind10/pdf/c04.pdf 
ing Grubel-Lloyd index to compute the IIT index:

$$
I I T=1-\frac{|X-M|}{(X+M)}
$$

Substituting (13) into (14) and using $h=\frac{b}{b^{*}}$, we get

$$
I I T=\frac{2 k h}{4 h+k}
$$

Proposition 2: The IIT share is higher between countries with similar technology levels.

Proof: By formula (15), we have $\frac{\partial I T T}{\partial k}>0$. This means that the IIT index is large when $\mathrm{k}$ approaches 1 (recall that $\mathrm{k}$ is the relative similarity in technology level between the two countries, so $\mathrm{k}$ approaching 1 carries the meaning that Home and Foreign are similar in terms of technology). Put differently, IIT index is higher between countries that have similar technology levels. Note that whereas in proposition 1 trade volume may be low, proposition 2 implies the intensity of IIT (share) should always be high when $\mathrm{k}$ approaches 1 .

Proposition 3: The IIT share is higher between countries with similar level of income.

Proof: Formula (15) gives us $\frac{\partial I I T}{\partial h}>0$. This means that IIT increases with increasing $h$. A higher $h$ value means that $b$ and $b^{*}$ become more similar, or the two countries are more similar with regard to per capita income.

The propositions 2 and 3 above can be visually shown in Figure 2, which is derived from equation (15). We can observe that the IIT index increases with increasing values of $k$, and that the IIT index becomes higher with higher values of $h$. Remember that a higher value of $k$ implies more similar in terms of technology levels between the two countries, and that a higher value of $h$ implies more similar in terms of per capita income between the two countries.

\section{Conclusions}

We have modeled the roles of $R \& D$ investments for quality innovation and country similarities in per-capita income and technology on vertical intra-industry trade. Our principal findings are as follows.

First, the volume of trade is higher among countries in which R\&D investments for quality innovation are higher. Second, we found that the IIT index between countries with similar levels of technology is higher than that between those with differing levels of technology. Finally, the IIT index was shown to be higher between countries with similar levels of per-capita income.

Countries with similar per-capita income or with similar technology can be considered to be at similar development levels. Thus, our theoretical findings may help explain recent empirical findings that world trade is more concentrated among the developed countries.

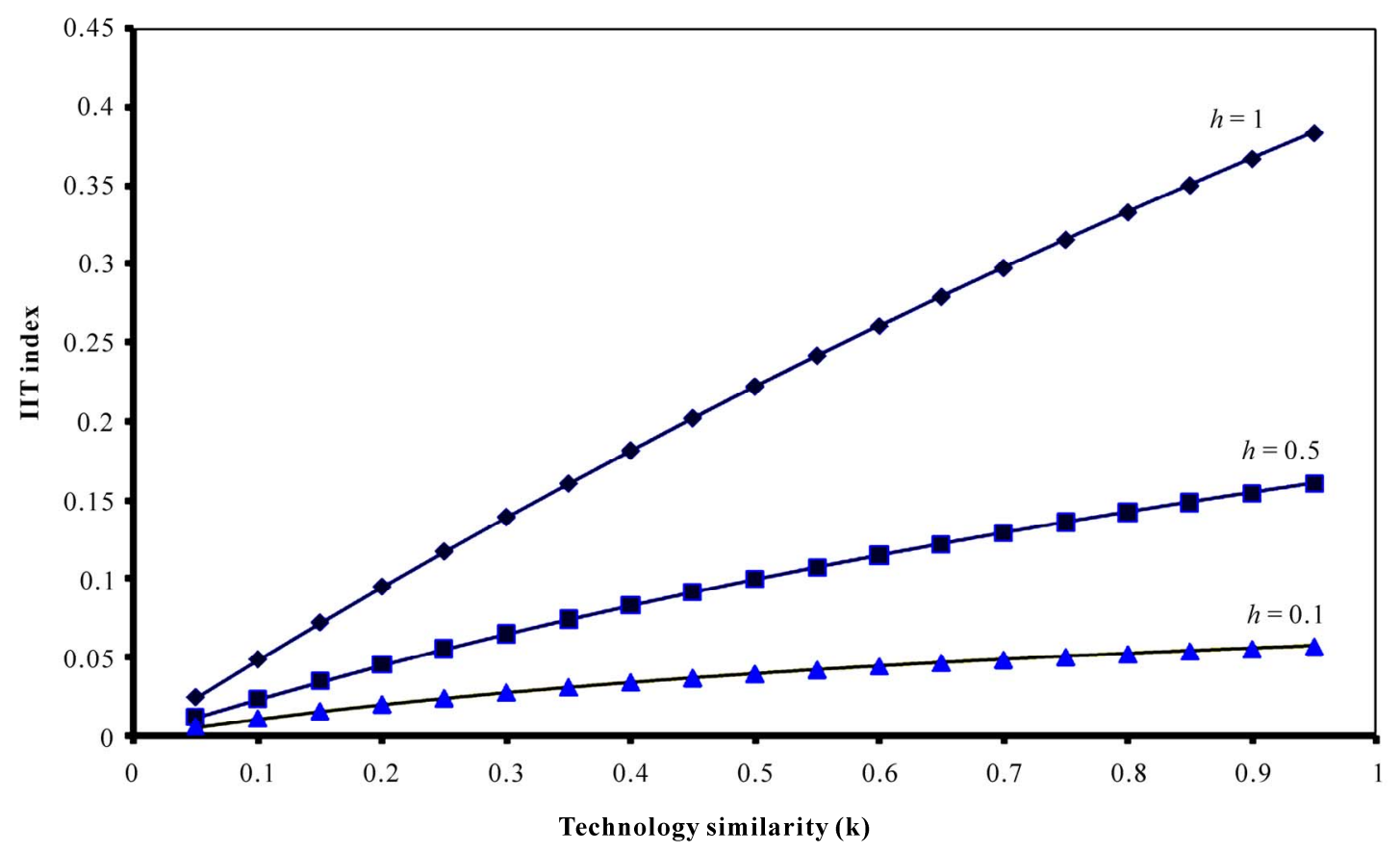

Figure 2. IIT share and country similarity in technology and income. 


\section{Acknowledgement}

We are grateful an anonymous referee for helpful comments. We also wish to thank Kim Humphreys for English editing. All errors are ours.

\section{References}

[1] R. Bergoeing and T. J. Kehoe, "Trade Theory and Trade Facts,” Federal Reserve Bank of Minneapolis Research Department Staff Report No. 284, 2003.

[2] H. Gabrisch and M. L. Segnana, "Vertical and Horizontal Patterns of Intra-Industry Trade between EU and Candidate Countries," IWH-Sonderheft, Halle Institute for Economic Research, 2003.

[3] P. Krugman, "Increasing Returns, Monopolistic Competition, and International Trade,” Journal of International Economics, Vol. 9, No. 4, November 1979, pp. 469-479.

[4] K. Lancaster, "Intra-Industry Trade under Perfect Monopolistic Competition,” Journal of International Economics, Vol. 10, No. 2, May 1980, pp. 151-175.

[5] H. Flam and E. Helpman, "Vertical Product Differentiation and North-South Trade," The American Economic
Review, Vol. 77, No. 5, December 1987, pp. 810-822.

[6] J. C. Hallak, "A Product-Quality View of the Linder Hypothesis," The Review of Economics and Statistics, Vol. 92, No. 3, August 2010, pp. 238-265.

[7] S. Linder, "An Essay on Trade and Transformation," Wiley, New York, 1961.

[8] T. Kim and L. D. Niem, "Product Quality, Preference Diversity, and Intra-Industry Trade," The Manchester School, forthcoming, 2010.

[9] J. Gabszewicz, and J. F. Thisse, "Price Competition, Quality and Income Disparities,” Journal of Economic Theory, Vol. 20, No. 3, June 1979, pp. 340-359.

[10] X. Wauthy, "Quality Choice in Models of Vertical Differentiation,” The Journal of Industrial Economics, Vol. 44, No. 3, September 1996, pp. 345-353.

[11] L. Beloqui and J. M. Usategui, "Vertical Differentiation and Entry Deterrence: Reconsideration,” WP 2005-06, Dept. Fundamentos del Analisis Economico II, Universidad del Pais Vasco, 2005.

[12] E. Helpman and P. Krugman, "Market Structure and Foreign Trade: Increasing Returns, Imperfect Competition and the International Economy,” Wheatsheaf Books, Brighton, 1985. 